\title{
CADA UM CAMINHA POR ONDE PODE, POR ONDE LHE É POSSÍVEL CAMINHAR: ENTREVISTA A JOÃo RIBEIRO
}

\author{
Ana Cristina Pereira
}

Encontrei-me o cineasta moçambicano João Ribeiro numa esplanada da cidade de Maputo, numa manhã de abril, cedinho, que a vida por ali não pode esperar até à hora do calor. Durante a conversa tornou-se evidente a forma como os fios da história do cinema moçambicano se imbricam nos da vida do autor e como perceber tudo o que generosamente revela implica compreender o contexto em que se desenvolveu o seu percurso. Filho de pais cabo-verdianos nasceu em 1962, em Quelimane. João Ribeiro tinha 13 anos aquando da Independência de Moçambique.

Durante os primeiros quinze anos da Independência de Moçambique, o cinema esteve integrado na estratégia política do governo do país: entre 1975-1991, o Instituto Nacional de Cinema (INC) dominou o mundo do cinema em Moçambique em todas as suas fases desde a produção e distribuição até exibição de filmes. O cinema, sob tutela do ministério da informação, era controlado pelo secretariado do Departamento de Informação e Propaganda (DIP) e criou-se um circuito nacional de distribuição de filmes, controlado e dirigido pelo partido, dedicado à divulgação de filmes produzidos e realizados pelo INC/DIP e outros filmes (russos, italianos, etc.) com a mesma orientação política (por exemplo, Convents, 2011). João Ribeiro ainda em Quelimane foi Delegado Provincial do INC gerindo um conjunto de 5 salas de cinema espalhadas pela província, ao mesmo que tempo alimentava o hobby da fotografia e começava a trabalhar com vídeo.

O governo moçambicano, nesta altura, apoiava os movimentos de libertação da Rodésia e a luta contra o apartheid na África do Sul, o que se traduziu em termos internos numa guerra civil que devastou o país. Quando a Rodésia deu lugar ao Zimbabwe, as forças do país vizinho lutaram ao lado da Frelimo (Coelho, 2004). Em 1987 João Ribeiro muda-se para a cidade de Maputo onde, ainda no INC, foi chefe do arquivo de filmes e mais tarde coordenador de produção. Nos anos 80, a televisão chega a Moçambique e João Ribeiro passou por três dos mais importantes canais nacionais onde foi responsável pelo processo de instalação, modernização, criação de conteúdos nacionais, produção de programas e eventos. Parte para Cuba em 1989 onde, em 1991, se forma em Realização e Produção na Escola Superior de Cinema e Televisão de San António de los Baños.

Ao mesmo tempo a guerra e a degradação das condições económicas no país dificultavam, cada vez mais, a produção e a importação de filmes. A falta de investimento levou à deterioração das salas de cinema e na segunda metade dos anos 80 a qualidade $e$ a quantidade do cinema que se podia ver em Moçambique decresceu substancialmente. Para piorar a já de si frágil situação da produção cinematográfica em Moçambique, no início da década, um incêndio deflagrou no INC reduzindo a cinzas praticamente todo o arquivo de filmes, de material de produção e de espaços. 
Nos anos 90 do século passado, a economia moçambicana e com ela os meios de comunicação social são liberalizados. Os cineastas oriundos do INC e da Kanemor estão na base da formação das empresas que são a espinha dorsal da produção de cinema no país até aos dias de hoje. $\mathrm{O}$ acesso à nova tecnologia digital facilitou o aparecimento de novas oportunidades e, fazendo da união a sua estratégia de sobrevivência, os elementos destas pequenas empresas ocupam-se de tudo: produzem, realizam, filmam, etc., os projetos uns dos outros. João Ribeiro de regresso a Moçambique junta-se à Ébano Multimédia onde, desenvolve, produz e realiza vários documentários para cinema e televisão. É na Ébano que se torna membro fundador da Southern Africa Communication for Development uma das primeiras organizações regionais de produtores independentes. Em 2000 João Ribeiro cria a COOL (produtora independente).

No entanto, a degradação provocada pela guerra, e sobretudo o abandono de políticas protecionistas ao cinema, conduziram o cinema moçambicano a uma crise profunda. Deste modo, torna-se hoje mais difícil estabelecer em Moçambique um centro de produção cinéfila com a importância e a independência que teve nos anos 70 e que afirmava, inclusivamente, uma perceção diferente da história, do mundo e da arte (Por exemplo, Watkins, 1995). O "cinema mundo" produzido em Moçambique - rótulo que é atribuído pelos centros decisórios, ou seja, o norte do continente americano e a Europa (Dennison \& Lim, 2006) - encontra-se hoje dependente dos circuitos internacionais de financiamento e do conceito de coprodução. João Ribeiro é o realizador do Último Voo do Flamingo (2011) que teve a sua estreia no Pavilhão do Mundo no Festival de Cinema de Cannes e foi selecionado por alguns dos maiores Festivais de Cinema do Mundo tornando-se no primeiro filme Moçambicano a ter estreia comercial além-fronteiras.

\section{EnTrevista A JoÃo Ribeiro - MAPUTo, 19 DE ABRIL de 2016}

Ana Cristina Pereira (ACP) - Como é que começaste a fazer cinema?

João Ribeiro (JR) - Eu comecei a fazer cinema através da fotografia. Eu tinha um laboratório, entrei na imagem através disso... às vezes até costumo dizer que entrei na imagem através de ver filmes. Dantes tu ias ao cinema tinhas os cartazes cá fora, aquelas fotografias de cena e nós, putos, imaginávamos a história que víamos nos cartazes, porque não podíamos entrar. Inventávamos a história vendo cartazes. Parece-me que foi essa a forma de começar a fazer cinema; ver, discuti-lo, conversar e depois então a fotografia e mais tarde comecei a fazer vídeo, depois televisão. Comecei a editar em vídeo em casa, cortava fita magnética e colava... ainda se trabalhava em VHS... em casa, de forma doméstica. E depois tive oportunidade, então sim, de começar a trabalhar num estúdio de cinema. E aí comecei primeiro na distribuição, na exibição, na gestão e depois passei ao arquivo de filmes, passei então à produção, mas sempre ligado à televisão. Fazendo um programa de televisão, ainda antes de trabalhar em produção de cinema propriamente dito, não é? Isso desde... comecei a fazer fotografia cedo, tinha 15 anos ou

'A Kanemo foi uma produtora criada oficialmente em 1983 para suprir as necessidades de produção cinematográfica do país, uma vez que o INC não conseguia responder a todas as demandas (Nogueira, 1986). 
14 anos quando comecei a fazer fotografia, mas comecei a trabalhar na televisão em 85 . No início em televisão fazia matérias, na minha cidade em Quelimane, que eram depois usadas pela TVM na altura, quando dava reportagens daquilo que acontecia lá na província, mas mais do ponto de vista da imagem, não do ponto de vista jornalístico. Até chegamos a fazer um pequeno programa que depois enviávamos para cá.

$A C P$ - E depois foste para Cuba, já no final dos anos 80 ?

JR - Sim em 89/90 fui para Cuba e aí sim estudei cinema e televisão. Produção e realização.

$A C P$ - Ficaste lá quanto tempo?

JR - O curso era dois anos, não é? São dois anos. Na altura. Agora são três, mas na altura eram dois anos.

$A C P$ - E quando chegaste a Moçambique? Foi numa altura um pouco difícil aqui. Como foi a reintegração?

JR - Sim. Quando cheguei a Moçambique o Instituto de Cinema estava parado. Tinha havido aquele incendio... fazia um ano... quase um ano... aquilo era um marasmo total. Não havia atividade nenhuma no Instituto de Cinema. As pessoas encontravam-se lá fora, mas também ao mesmo tempo essas mesmas pessoas já tinham começado a fazer algumas coisas de forma individual. Tinham aberto uma cooperativa que na altura era a Copymagem; tinham feito uma cooperativa onde já estavam a fazer algum trabaIho. Havia a Ébano Multimédia que já tinha sido constituída pelo Pedro Pimenta, Sol de Carvalho, o José Luis Cabaço e o Licinio Azevedo. Como eu tinha vindo antes fazer a minha curta, porque eu fiz um filme ainda aqui na escola... vim fazer uma coprodução que era a minha tese; vim com colegas fizemos uma curta-metragem aqui em cinema e utilizei... fiz uma coprodução entre a Escola, a Kanema e o INC, porque fui estudante enviado pelo Instituto Nacional de Cinema, não é? Como trabalhador do INC, então fiz esta coprodução, este pequeno filme, com a Escola onde estava em Cuba, a Kanema e o INC. E nesta altura, já conhecia, mas aproximei-me muito do Pedro (Pimenta) que era o diretor geral da Kanemo. Mesmo nessa altura ele já tinha dito que já tinha intenções de criar uma empresa com o Licínio e tal e que quando eu regressasse provavelmente me poderia juntar eles, poderíamos trabalhar em conjunto.

Então quando eu venho de Cuba e encontro essa situação, a primeira coisa que me ocorreu foi imediatamente começar a trabalhar e continuar a produzir, não é? Então nessa altura pedi ao Instituto de Cinema férias sem vencimento - havia pessoas a receber, na altura. Sem fazer nada. Havia muitos. Todos os trabalhadores do INC, não tinham trabalho, mas recebiam. Eram profissionais do cinema - $\mathrm{Na}$ altura eu pedi, também com mais uma ou duas pessoas, provavelmente, pedi férias sem vencimento e portanto até hoje, estou de férias sem vencimento (risos). Pedi uma licença ilimitada, digamos assim... e comecei a produzir um documentário, na altura, um documentário que tinha montado em projeto e fui trabalhar na Ébano. Não com a Ébano, na Ébano, portanto eles já tinham o espaço, fiz lá uma... aluguei uma sala e montei uma espécie de uma pequena produtora, mas trabalhando dentro da Ébano. Fiz esse projeto, demorei algum tempo, durante esse processo de produção aproximei-me ainda mais do Pedro, do Licinio, do 
Cabaço, do Sol... e começamos a trabalhar em conjunto, portanto eu comecei a fazer projetos deles. Depois o Sol saiu da Ébano para abrir a Promarte e na altura eu fiquei com a cota dele na Ébano e então juntei-me a esse grupo. E depois nunca mais... voltei depois para o cinema. Depois fiquei independente... trabalhei na Ébano e depois noutras produtoras. Foi esse o processo de integração pós-escola...

ACP - As questões políticas que envolvem o cinema. És menos ligado a isso do que os outros, talvez por seres mais novo? Ou não é verdade que sejas menos envolvido politicamente?

JR - Isso é uma análise que tu estás a fazer...

$A C P$ - Estou a fazer uma pergunta.

$J R$ - Eu acho que todos nós temos uma responsabilidade política. E eu acho que todos os meus filmes têm uma vertente crítica de análise bastante forte. Eu só faço ficção como realizador, mas como produtor, trabalhei em inúmeros projetos de produção todos eles com grande conotação política. Acho que nenhum filme que eu tenha feito se possa dizer que não tem... todos os documentários, a maior parte dos documentários são sobre "Verdade e reconciliação" paz, guerra... xenofobia... acesso à água... condições de vida... eu tenho duas vertentes, sou produtor e sou realizador. Como realizador gosto de realizar ficção, não gosto de realizar documentário. Sinto que não sou uma pessoa do documentário. Gosto de realizar ficção, gosto de orientar atores, gosto de trabalhar no guião, gosto de trabalhar na preparação. Gosto de trabalhar ficção. Como cineasta, como produtor os meus projetos são vários: trabalho em ficção e trabalho em documentário, portanto fiz inúmeros documentários que produzi eu próprio, que coproduzi ou que prestei serviço para. E mesmo nesses filmes de ficção que faço, as temáticas escoIhidas são, tirando uma das curtas, por exemplo $O$ Último voo do Flamingo é um filme político, quer dizer, é uma história de ficção, mas é uma história que conta o processo de pós-guerra, onde há críticas bastante fortes à governação, ao passado... portanto acho que todos nós temos essa capacidade ou essa responsabilidade. Digamos assim, portanto o facto de fazer entretenimento ou de fazer um filme de ficção, não quer dizer que ele não possa ter uma conotação política, ou às vezes até ter mais do que um que aparentemente... que o objetivo é essa vertente.

ACP - O Último voo do Flamingo é um filme pós-colonial?

JR - Sim. Essa abordagem... se olharmos para o tempo em que ele foi feito, para o momento em que ele foi feito e a temática que ele aborda, obviamente que ele está numa fronteira, não é? Numa passagem de tempo, nós estamos ali num momento em que viemos das lutas de libertação para uma independência, passamos de uma independência para uma outra luta interna, uma luta fratricida [profere esta última palavra com particular violência], não é? Uma luta... uma guerra civil! Posteriormente a essa guerra há todo um novo renascimento, digamos assim, há uma paz, há a entrada de novos poderes, não é? Desta força das Nações Unidas (ONU), desse poder mundial que vem estabilizar, ou estabelecer uma nova nomenclatura, um novo estado, não é? Uma nova ordem, portanto, obviamente que tem essa leitura, essa é a leitura política, esse é o posicionamento. Sim concordo. Não sei se será pós-colonial [risos - por causa da celeuma 
que a palavra provoca nestas paragens...] mas que aborda essa temática obviamente. $\mathrm{E}$ que fala de uma nova espécie de colonialismo, de uma nova espécie de poder dominante e do papel desse poder perante a sociedade, obviamente e questiona esse poder. Portanto: quem são vocês, quem são esses que veem com ONU na testa e que veem pôr...

ACP - Seria extrapolar muito dizer que essa reflexão que fazes sobre a sociedade e sobre a política em geral, também se aplica ao cinema... e que o cinema que fazes, neste caso, de agendas internacionais e de poderes e interesses que ultrapassam as tuas necessidades enquanto criador e as necessidades que sentes no público de cá?

JR - [visivelmente gaguejante dada a delicadeza do tema da pergunta] Há posturas... quer dizer... é um pouco... contraditório, no sentido em que se pode fazer um filme sem nada. Já dizia Glauber Rocha... uma câmara no ombro e uma ideia na cabeça e vamos fazer um filme. Esse filme pode ser o melhor filme do mundo, ou seja, não quer dizer que a falta de recursos, ou a falta de meios financeiros, ou meios técnicos impeçam a realização de uma boa obra de cinema. Agora, são percursos, cada um escolhe o seu... cada um caminha por onde pode, por onde lhe é possível caminhar. Se me ponho num projeto de ficção, se me ponho num projeto, quero fazer um filme com este grupo de trabalho, quero ter equipa, quero ter meios, quero ter capacidade de produzir de criar de... quero ter essa experiência de cinema, não essa experiência de uma câmara na mão... e... também já tive essa experiência. Já participei nesse tipo de projeto e gosto. Quando vamos fazer um documentário, gosto de ter essa experiência reduzida de poucas pessoas, de improvisar, etc. mas para fazer o cinema curta-metragem ou longa que eu quero fazer, eu aposto nesse tipo de projeto. Que tem essa implicação que tem essa via, mas não é a única. Não quer dizer que isso seja um carimbo e que essa seja a única forma de fazer.

Portanto eu não estou preocupado com a quantidade de filmes que vou fazer em vida... quero fazer os projetos que eu sinto simpatia por, portanto não tenho problemas em seguir esse caminho: em ir à procura desse financiamento e estar nessa dependência, mas há outros caminhos... é preciso entendermos esta possibilidade, porque se eu tiver uma câmara e eu tiver dois atores e eu tiver o mínimo de condições eu posso fazer um filme. Posso contar uma história e nada contra. Agora este é o caminho que eu quero.

Estou a desenvolver um outro projeto. Este primeiro, esta minha primeira longa demorou 10 anos a aparecer na tela, entre a ideia e a sua exibição, se calhar este segundo projeto vai demorar 8, 10 ou 12, mas não estou preocupado com isso porque quero fazê-lo da mesma maneira, quero ter equipa, quero ter dinheiro, e aí claro não há outra saída porque infelizmente em Moçambique e dentro do nosso horizonte não há formas de financiamento, não há formas de produção, não há formas de exibição que não sejam essas de ir buscar dinheiro lá fora e de estar dependente dessas agendas, das agendas de quem dá. De quem dá o dinheiro, portanto que tipo de filme é que estão à procura de ver na tela, que tipo de países é que vão apoiar. Isso também faz parte do processo de decisão... porque se apoiaram muitos filmes de Moçambique o ano passado não vão apoiar mais este ano. Quer dizer há todo um conjunto de coisas... não é só um projeto bom. Teoricamente é: passa o melhor projeto, mas o júri é constituído por muitas 
pessoas, essas pessoas, cada uma dessas pessoas tem a sua agenda, tem o seu objetivo e essas dependências existem, mas é a regra do jogo.

ACP - E depois de conseguir o dinheiro, sentiste muita pressão da produção no teu trabalho, ou foste livre?

JR - Eu acho que isso não existe. Acho que essa liberdade é o sonho, acho que todos nós... o realizador para ter essa liberdade tem que ser ele o detentor da maioria do dinheiro financiado, por isso é que há muitos realizadores americanos e realizadores de ficção que são produtores dos seus próprios filmes, eu também fui só que a minha participação no filme não é maioritária. O dinheiro que eu como Moçambique consegui não é... não me dá essa capacidade, portanto neste jogo de produção, neste conjunto de fatores que implica lidar com vários produtores de todos os países financiadores, cada um com a sua participação, tens que fazer compromissos, tens que saber gerir todo esse processo, do qual tu fazes parte, se calhar, em posição menos importante. Do ponto de vista criativo sim, do ponto de vista estético sim, mas do ponto de vista do financiamento e do dinheiro não. Portanto essa liberdade não existe, não é? $E$ acho que é assim que tem que ser, porque profissionalmente tem que se trabalhar em coordenação e tem que haver dependências de decisões de todas as partes, porque as decisões custam dinheiro, não é? As opções custam dinheiro e é preciso chegar ao fim do projeto e é preciso às vezes comprometer um pouco: isto é o ideal, mas não conseguimos chegar lá. Temos de trabalhar assim porque se não, não vamos acabar. Ou temos que pôr... as pressões vêm de todo o lado, é o tipo de enfase que dás a uma frase, é o tipo de imagem que mostras numa cena, é no tipo de ator que vais escolher... tudo isso é um jogo complexo...

ACP - As equipas depois também... todos querem meter alguém do seu país... seja ator, caracterizador...

JR - Sim, alguns países que te obrigam a cumprir regras, não é? Por exemplo tens um financiamento francês tens que ter $x$ pontos, para teres esses pontos tens que cumprir certos preceitos, tens que ter um... não quer dizer que tenhas que ter um operador de som, mas tens que ter um operador, tens que ter um técnico, tens que ter um artista, tens que ter uma parte criativa, ou tens que ter fazer qualquer coisa e isto te dá valor dentro da coprodução. Também não faz sentido fazeres uma coprodução para ires buscar dinheiro, achando que não deve ser assim, porque quem dá não vai obter dinheiro de volta. Isso funciona num projeto comercial, vamos fazer um filme para vender, vamos ter muitos bilhetes, vamos ter muitas pessoas e vamos dividir lucro. Aí é óbvio que a participação criativa pode ser um fator de menor importância para quem põe o dinheiro, agora nos casos em que estes filmes são feitos para a nossa audiência e os filmes não têm como objetivo primário fazer um retorno financeiro, os países que investem têm que ter um retorno criativo. Dizem não: nós vamos pôr este dinheiro, mas queremos que também haja franceses a trabalhar, queremos que haja brasileiros a trabalhar, queremos que haja artistas, meios técnicos, serviços de produção que sejam prestados por esses países.

$A C P$ - E a ti dá-te prazer fazer esse tipo de jogo?

JR - Sim, claro. Eu acho que só ganhamos com isso. Eu acho que se também tivesse a possibilidade de financiar alguma coisa onde não vou ter retorno financeiro, 
também gostava de ter uma influência sobre esse processo criativo. Quer dizer obviamente dentro do limite desse investimento e respeitando a obra inicial que nos chamou a investir. Portanto, há uma ideia, essa ideia atrai um investidor, há que haver respeito por essa ideia, porque se não também não valia a pena investir, não é? Portanto se respeitas a ideia e se confias na capacidade de liderança, ou na capacidade de execução dessa equipa, vais financiar, a tua participação tem que ser gerida dentro desse princípio, se queres alterar o projeto, se queres fazer outra coisa então é melhor encontrares um outro realizador, ou uma outra equipa de produção, não é? Funciona assim, claro a mim dá-me prazer, porque é uma coisa complexa... é todo um processo. É desde o guião, desde o que tu escreves no guião, até ao processo de pós-produção tudo passa por essa discussão. É preciso que os teus coprodutores estejam contentes com o teu corte, é preciso que os teus coprodutores estejam contentes com a ficha técnica, com a música, com a cor do filme, com... quer dizer há todo um enorme conjunto de fatores que tu tens que saber gerir. Por princípio, A não ser que tenhas a sorte de te dizerem: eh pá faz o que tu quiseres... sorte ou azar, porque às vezes fazes o que tu quiseres e fica uma coisa que não atinge nenhum objetivo... acho que da discussão e da participação coletiva nascem coisas boas, não é? Obviamente que não é o único caminho.

ACP - Moçambique está num momento bom para a ficção... um filme por ano...

JR - Pá... eu não sei se um filme por ano é um ritmo... porque um filme por ano é um realizador a fazer um filme, não é?

ACP - Mas num país que chegou a estar anos e anos sem produzir uma longa de ficção...

JR - Mas também já fizemos cinco e seis por ano, filmes nacionais e estrangeiros... Agora não só não temos produção nacional, como não temos ficção a ser filmada em Moçambique de outros países, não é? Portanto há uma retração grande... isso não considero que seja um bom momento. E se virmos também que esses projetos são oportunidades que acontecem, porque por exemplo, este filme do Sol vem dentro do Doc TV e do Film TV que é uma coisa que aconteceu da última vez faz três anos ou quatro, portanto não sabemos se para o ano vai haver ou se vai demorar outra vez mais três ou quatro anos para haver outra vez essa possibilidade de financiamento. O filme do Licínio vem duma situação diferente há um concurso anual em Portugal onde ele recebeu algum dinheiro e depois foi buscar, como eu fiz da outra vez, a outros fundos internacionais, eu tenho este filme também financiado por Portugal, grandemente por Portugal, tenho que arranjar o resto do dinheiro, aí tu tens um fundo que tu sabes que todos os anos podes concorrer... ganhas ou perdes, mas é uma coisa cíclica. Agora este outro concurso é meramente esporádico, aconteceu. Portanto eu não sei se termos essa média de um filme por ano, nos últimos dois anos, mas de há dois aos para traz não se filmou também nada durante três ou quatro... portanto se fizermos essa conta nos últimos 10 anos, vai dar um filme a cada três ou quatro anos... e isso não é bom para nenhum país do mundo. Acho que o cinema faz parte do processo cultural, do processo de registo da vida do país e a falta desses filmes será uma lacuna para a história do futuro. As pessoas não vão ter essa história, essa memória... da ficção, da fantasia, não é? Desse tipo de crítica, 
de sátira, análise de outra forma da vida das pessoas. Eu não acho que seja um bom ritmo, acho que é um ritmo bastante baixo, e acho que a tendência é decrescer porque cada vez há menos financiamento e cada vez a geopolítica mundial também sofre, não é? Estamos cheios de crise, e isso tem influência direta. Por exemplo, o meu filme tem financiamento desde o ano passado e não tem contrato assinado, portanto eu nem sei se vou filmar para o ano ou daqui a dois anos. O ICA ${ }^{2}$ ainda não assinou contrato, portanto não assinou o contrato, não liberou verba, portanto não tendo esse contrato não posso ir a outros financiadores pedir o que falta, porque não tenho como provar que já tenho algum fundo garantido... e já vai fazer um ano, já está a abrir-se um segundo concurso e ainda não assinaram contratos do concurso anterior. Portanto essa crise internacional afeta esta produção, se nós produzimos pouco e se dependemos desse financiamento então menos iremos produzir.

ACP - Estás pessimista em relação ao futuro?

JR - Se falares do cinema sim. Porque não se vê também na televisão nenhum movimento no sentido de criar oportunidade. Portanto a televisão em Moçambique tem 36 anos, tem 10/15 anos televisão privada não há nenhuma iniciativa nessas televisões para criarem uma opção, um caminho para a produção para o incentivo de ficção nacional, não há teatro na TV, não há drama na TV, não há séries nacionais, não há nenhum indicador de que isso possa passar. Não há movimentos do governo, há uma lei de patrocínio que permite que as empresas façam alguns financiamentos na cultura. Essa lei não é divulgada, não tem um regulamento, as pessoas não sabem como utilizar, não acreditam que isso exista, que isso funcione, é preciso fazer um trabalho pedagógico junto das instituições, mesmo assim as instituições não liberam o dinheiro com base nela, não acreditam porque depois as finanças vêm cobrar que eles dizem já ter pago através deste financiamento, portanto enquanto não houver todo um conjunto de leis e de regulamentos que permitam que haja investimento para a área do cinema esta situação não vai mudar.

ACP - Havia uma taxa, que permitia constituir um fundo, mas desapareceu, certo?

JR - Havia uma taxa que era cobrada no bilhete de cinema, o dinheiro dos bilhetes de cinema todo ele ia parar ao INC

ACP - Não tinha a ver com a televisão?

JR - Não, nunca teve a ver com a televisão. Havia o INC que era também distribuidor e exibidor ele próprio, não é? E havia um valor de cada bilhete que iria para constituir um fundo de produção. Mas isso já não existe há 30 anos isso acabou...

$A C P$ - E a escola? Não há uma escola de cinema em Moçambique...

JR - Agora existe dentro da ECA um curso de cinema. Tem um curso de cinema que começou este ano

$A C P$ - Eu perguntei quando lá estive, ninguém sabia desse curso lá... ninguém me falou desse curso lá... de quantos anos é o curso?

JR - Penso que são três anos. Há também uma academia de audiovisual que forma algumas pessoas ligadas mais à parte operacional, mais à parte técnica de produção, do

\footnotetext{
${ }^{2}$ Instituto Cinema e Audiovisual (Portugal)
} 
que propriamente à parte criativa ou à parte de gestão de conteúdos, ou à parte de escrita... mas acho que isso não é o caminho... acho que isso é muito importante sim senhora é uma abertura de portas é um sinal mas não pode ser o único, acho que a formação não pode passar só pela criação de um estudo, de um curso superior de cinema, que vai formar uns teóricos, pessoas que não vão ter o mínimo contacto com a produção.

ACP - Por quê? Não fazem filmes lá os alunos?

JR - Não sei vamos ver o que vai acontecer, é o primeiro ano tem um curriculum, vai formar pessoas, mas não acredito que essa seja a única via ou que seja a via mais democrática digamos assim, mais democrática no sentido de espalhar a de massificar a produção. Porque teria que haver outro tipo de formação. Uma formação mais na base, dentro da escola o audiovisual devia fazer parte... temos uma escola de artes visuais, que ensina a desenhar e essas coisas, mas isso devia fazer parte do curriculum desde criança as artes visuais... aqui não é assim.

$A C P$ - Não há educação visual na escola pública em Moçambique?

JR - Não, não há, não há. Portanto se tivesses essas aulas e esses ciclos de formação de interesses e outros cursos paralelos ai a coisa poderia mudar de figura e teres mais pessoas interessadas no audiovisual. Agora só um curso superior... não pode ser visto como a solução do problema... tem que se fazer um investimento anterior. Desde a escola primária, projeções, etc. há todo um trabalho que é importante fazer, se não há cultura visual como é que pode haver cinema? São poucas as escolas que têm esse caminho... talvez uma escola privada ou outra possa ter, projeções de cinema de forma regular, mas o normal é muito esporádico. OK há um filme que passa um dia... não há regularidade que possa despertar um interesse genuíno. Não há cinema em salas comerciais. Só há uma sala comercial a exibir, uma na Matola outra em Maputo, no resto do país não há. É caro. Portanto, as pessoas veem cinema onde? Na TV... existe pouco. Também é uma forma de ver... mas é raro passarem.

\section{FinANCiAmento}

Esta entrevista está inserida numa investigação de doutoramento em estudos culturais, cujo tema é "Alteridade e identidade no cinema pós-colonial em Portugal e em Moçambique", financiada pela Fundação da Ciência e Tecnologia, no domínio das Ciências da Comunicação, com a referência SFRH/BD/110044/2015

\section{REFERÊNCIAS BIBLIOGRÁFICAS}

Coelho, J. P. B. (2004). A "literatura quantitativa" e a interpretação do conflicto armado em Moçambique 19761992. Maputo: Universidade Eduardo Mondlane.

Convents, G. (2011). Os Moçambicanos perante o cinema e o audiovisual. Maputo: Dockanema.

Dennison, S. \& Lim, S. H. (2006). Situating world cinema as a theoretical problem. In S. Dennison \& S. H. Lim (Orgs.), Remapping World Cinema (pp. 1-15). Londres: Wallflower.

Nogueira, T. S. (1985). Kanemo: um projecto de cinema. Revista Tempo, 44-45. 
Watkins, C. A. (1995). Le cinema africain lusophone: perspectives historiques et contemporaines de 1969 à 1993. Ecran d'Afrique, 13/14, 109-124.

\section{NOTA BIOGRÁFICA}

Ana Cristina Pereira é doutoranda em Estudos Culturais no Centro de Estudos de Comunicação e Sociedade da Universidade do Minho (CECS/UM); Mestre em Ciências da Educação pela Universidade de Aveiro; Licenciada em Teatro pelas escolas de Teatro e Cinema de Lisboa e de Música e Artes do Espetáculo do Porto. Com investigação sobre cinema, raça e género, é Bolseira FCT em regime misto.

Email: ana.c.pereira@outlook.com

Centro de Estudos de Comunicação e Sociedade, Instituto de Ciências Sociais, Campus de Gualtar, 4710-057 Braga, Portugal

* Submetido: 12/04/2017

* Aceite: 10/05/2017 